CLINICAL STUDY

\title{
Endothelial-mediated coronary flow reserve in patients with mild thyroid hormone deficiency
}

\author{
Bernadette Biondi $^{1}$, Maurizio Galderisi ${ }^{2}$, Loredana Pagano ${ }^{1}$, Milena Sidiropulos ${ }^{2}$, Melania Pulcrano ${ }^{1}$, \\ Arcangelo D' Errico ${ }^{2}$, Serena Ippolito ${ }^{1}$, Annalisa Rossi ${ }^{1}$, Oreste de Divitiis ${ }^{2}$ and Gaetano Lombardi ${ }^{1}$ \\ ${ }^{1}$ Departments of Clinical and Molecular Endocrinology and Oncology and ${ }^{2}$ Clinical and Experimental Medicine, University of Naples Federico II, \\ Via S. Pansini 5, 80131 Naples, Italy \\ (Correspondence should be addressed to B Biondi; Email: bebiondi@unina.it)
}

\begin{abstract}
Context: Although coronary flow reserve (CFR) is reduced in patients with subclinical hypothyroidism (SHypo), the endothelial response of coronary vasomotion has never been explored in this clinical setting.

Objective: To investigate the endothelial response of coronary flow in young and middle-aged patients with SHypo, without associated cardiovascular risk factors compared with healthy control subjects. Patients and methods: The study population consisted of 20 women (mean age 38.4+12.1 years) with newly diagnosed, untreated and persistent SHypo due to Hashimoto's thyroiditis. A total of 15 volunteers served as controls. Age, gender, body surface area, glucose, insulin levels, heart rate, systolic, diastolic, and mean blood pressure were similar in patients and controls. Body mass index was significantly higher in SHypo patients. Total cholesterol and low-density lipoprotein cholesterol, despite not significant, tended to be higher, and high-density lipoprotein cholesterol to be lower in SHypo. Coronary blood flow velocities were recorded in patients at rest and after the cold pressor test (CPT), a stimulus that can be considered totally endothelium-dependent. CFR was calculated as the ratio of hyperemic-to-resting diastolic peak velocities.

Results: Coronary diastolic peak velocities at rest did not differ between the two groups but were significantly lower after CPT in patients with SHypo, thereby resulting in a lower CFR. The difference remained significant after adjusting resting and CPT velocities for the respective mean blood pressures. TSH was inversely correlated with CFR in the pooled population.

Conclusion: Patients with SHypo without associated cardiovascular risk factors have a coronary endothelial dysfunction that appears in response to a physiological stimulus (the CPT).
\end{abstract}

European Journal of Endocrinology 161 323-329

\section{Introduction}

Endothelial dysfunction is an important, early, and reversible feature of atherogenesis $(1,2)$. There is evidence of endothelial dysfunction of peripheral vasculature in patients affected by overt or subclinical hypothyroidism (SHypo) (3-6). Moreover, serum thyroidstimulating hormone (TSH) levels have been found to be inversely correlated with endothelium-dependent dilatation (4). Endothelial dysfunction in patients with SHypo has been attributed to reduced nitric oxide (NO) availability when vascular reactivity was assessed with the perfused forearm technique (5). In this clinical setting, the alteration seemed to be only partially related to the degree of dyslipidemia and to other atherosclerotic risk factors $(5,6)$.

Non-invasive transthoracic ultrasound imaging of coronary blood flow is increasingly being used to identify derangements of coronary microcirculation at the level of coronary flow in the absence of epicardial coronary stenosis $(7,8)$. Pharmacological hyperemic vasodilatation induced by adenosine or dipyridamole is a reliable and highly reproducible technique with which coronary flow reserve (CFR) is evaluated by Doppler echocardiography $(9,10)$.

Only two studies have previously evaluated CFR in young and middle-aged patients with SHypo $(11,12)$. In the first study, in which adenosine was used as stressor, CFR was lower in overt or SHypo than in a control euthyroid group (11). In the second study, dipyridamole infusion induced a similar reduction of hyperemic coronary flow, and thus of CFR, in patients with SHypo and in normal subjects (12). It is noteworthy that both adenosine and dipyridamole induce a hyperemic stimulus that relaxes vascular smooth muscle cells in a fashion only partially dependent on endothelial function (13).

CFR can be measured also with the cold pressor test (CPT), which is a well validated, sympathetic stimulus able to induce hyperemic vasodilation that depends 
totally on the endothelial release of NO $(14,15)$. Under normal conditions, $\alpha$-adrenergically mediated CPT vascular smooth muscle vasoconstriction is counteracted by subsequent 'reactive' hyperemia-induced endothelium-dependent vasodilation. When the bioavailability of NO is reduced, the vasoconstrictor effect prevails and coronary blood flow does not increase or may even decrease despite the increase of cardiac work expressed as rate-pressure product. Endothelial dysfunction has a negative prognostic impact on the long-term outcome of coronary heart disease (16).

The present study was designed to investigate the endothelial response of coronary flow in young and middle-aged patients with persistent SHypo without associated cardiovascular risk factors (i.e. obesity, dyslipidemia, arterial hypertension, diabetes mellitus, or hyperinsulinemia) compared with healthy control subjects.

\section{Methods}

\section{Study population}

The study population consisted of 20 women (mean age $38.4 \pm 12$ ) with newly diagnosed, never treated, persistent SHypo. These patients were undergoing monitoring in our ambulatory service for euthyroid Hashimoto's thyroiditis, diagnosed by a positive test for serum anti-thyroid peroxidase antibodies and thyroid Doppler ultrasound. They later developed mild thyroid hormone deficiency (about 8-12 months before our study). SHypo was diagnosed on the basis of persistent TSH increase with free thyroid hormones within the normal range. Patients entered the study only if they had stable SHypo (as demonstrated by two thyroid hormonal profiles). A total of 15 healthy euthyroid volunteers recruited among the staff and their relatives of our departments served as controls. All participants gave their informed consent to the study, which was approved by the Ethics Committee of Federico II University Hospital of Naples.

None of the subjects had any systemic disease. Patients and healthy controls had a sedentary lifestyle; none had a history of arterial hypertension, diabetes mellitus coronary artery disease, valvular or congenital heart disease, cardiac rhythm abnormalities, hepatic or renal disorders, or a family history of coronary artery disease. None received any kind of medication. Subjects were also excluded from the study if they were smokers or had used any vasoconstrictive drugs. Moreover, we excluded patients with clear-cut obesity defined by body mass index $(\mathrm{BMI}) \geq 30 \mathrm{mg} / \mathrm{m}^{2}$ and dyslipidemia. Lipid metabolism abnormalities were diagnosed when total cholesterol was $>5.2 \mathrm{mmol} / \mathrm{l}(200 \mathrm{mg} / \mathrm{dl})$, low-density lipoprotein (LDL) cholesterol was $>4.14 \mathrm{mmol} / \mathrm{l}$ (160 mg/dl), high-density lipoprotein (HDL) cholesterol was $<0.9 \mathrm{mmol} / \mathrm{l}(35 \mathrm{mg} / \mathrm{dl})$, or triglycerides were $>1.8 \mathrm{mmol} / \mathrm{l}(160 \mathrm{mg} / \mathrm{dl})$.

Coronary artery disease was excluded on the basis of the clinical history plus a negative maximal exercise (treadmill) electrocardiography (ECG) test. All participants abstained from caffeine-containing drinks for at least $12 \mathrm{~h}$ before the tests.

\section{Assessment of thyroid status}

All blood samples for circulating serum free triiodothyronine $\left(\mathrm{FT}_{3}\right), \mathrm{FT}_{4}$, anti-Tg, anti-TPO, and $\mathrm{TSH}$ were collected from the antecubital vein between 0800 and $0900 \mathrm{~h}$ after an overnight fast. TSH levels were measured with the electrochemiluminescence immunoassay (ECLIA; Elecsys and Cobas analyzers, Roche Diagnostics), which has a sensitivity of $0.005 \mathrm{mIU} / \mathrm{l}$ or less, and the normal range was 0.27-4.2 mIU/l. Serum $\mathrm{FT}_{3}$ and $\mathrm{FT}_{4}$ were also measured with the ECLIA. Sensitivities were $<0.400 \mathrm{pmol} / \mathrm{l}$ and $<0.300 \mathrm{pmol} / \mathrm{l}$ for $\mathrm{FT}_{3}$ and $\mathrm{FT}_{4}$ respectively. The normal ranges were $3.1-6.8 \mathrm{pmol} / \mathrm{l}$ for $\mathrm{FT}_{3}$, and $12-22 \mathrm{pmol} / \mathrm{l}$ for $\mathrm{FT}_{4}$.

Cardiovascular assessment The standard Doppler echocardiographic assessment and CFR test were performed on the same day, during the morning. Echocardiographic examinations were carried out with patients in a partial left decubitus position by a Vivid Seven AB Sound machine (GE, Horten, Norway) equipped with a $2.5 \mathrm{MHz}$ phased-array transducer with harmonic capability. At the end of the study, cuff blood pressure (BP; mean of three measurements) was measured by a physician blinded to the examination. M-Mode tracings were recorded in parasternal long-axis view, and left ventricle, left atrium and aortic root sizes were measured as previously reported (17). Left ventricular (LV) mass was calculated according to the American Society of Echocardiography recommendations and normalized for height in meters powered to 2.7 (18). Endocardial fractional shortening was calculated as the percentage change of LV internal dimension between systole and diastole. Standard pulsed Doppler imaging of mitral inflow was recorded in the apical four-chamber view. Early (E) and atrial (A) peak velocities $(\mathrm{m} / \mathrm{s})$ and their ratio, E velocity deceleration time (DT) and isovolumic relaxation time (IVRT; both in ms) were measured. Doppler echocardiographic methods and reproducibility of our laboratory are reported elsewhere $(19,20)$.

Coronary flow reserve The color Doppler visualization of coronary flow in the distal left anterior descending artery was obtained with a $5 \mathrm{MHz}$ shallow-focus phased-array transducer. Doppler sample volume was placed on the color signal of the left anterior descending 
artery, and the spectral pulsed Doppler signal was recorded to look for the characteristic biphasic flow pattern with a larger diastolic and a smaller systolic component both at rest and after CPT. Coronary diastolic peak flow velocities $(\mathrm{cm} / \mathrm{s})$ as well as heart rate and $\mathrm{BP}$ were measured at rest and soon after $\mathrm{CPT}$, corresponding to maximal hyperemia. CFR was calculated as the ratio of hyperemic-to-resting diastolic peak velocities. The CPT was performed according to a standardized protocol (21), by placing the subject's hand and distal part of the forearm in an ice water slurry for $3 \mathrm{~min}$. The highest three spectral Doppler signals were averaged for each parameter. We evaluated the reproducibility of our CPT-derived CFR measurements and obtained an intra-observer variability of $2.0 \%$ and an inter-observer variability of $4.5 \%$. All images were recorded on magneto-optical disks and analyzed off-line by two observers who were blinded to the clinical characteristics of the patients. All the examinations of coronary endothelial function were performed in the same period of the day (between 0800 and $0900 \mathrm{~h}$ ).

Our laboratory methods for the assessment of the CFR have already been reported $(22,23)$.

\section{Statistical analysis}

We used SPSS for Windows release 8.0 (Chicago, IL, USA) for statistical analysis. All the data are presented as mean values \pm s.D. The ANOVA test was used to assess intergroup differences. Linear regression analyses and the partial correlation test using Pearson's correlation method were used to test univariate relations. Differences were considered statistically significant at $P<0.05$.

\section{Results}

The demographic, clinical, and laboratory characteristics of the study population are shown in Table 1. TSH levels were significantly higher $(P<0.05)$ in patients than in controls. Although in the normal range, $\mathrm{FT}_{3}$ and $\mathrm{FT}_{4}$ levels tended to be lower in SHypo patients than in controls. Heart rate and systolic, diastolic and mean BP were similar in the two groups. BMI was significantly higher in SHypo patients versus controls. Insulin and glucose levels did not differ between the two groups, whereas total cholesterol and LDL cholesterol, although not significant, tended to be higher and HDL cholesterol to be lower in SHypo.

Table 2 shows the results of the Doppler echocardiographic analysis. LV structural measurements and parameters of LV systolic function did not differ between the two groups. Among the Doppler-derived diastolic parameters, IVRT and DT were significantly prolonged, which confirms previous results $(19,20)$.

The CPT was well tolerated by all subjects; there were no major adverse effects or symptoms, and no significant ECG changes. The results of the CFR test are shown in Table 3. Coronary diastolic peak velocities were similar at rest in the two groups but were significantly lower during CPT in patients with SHypo, thereby resulting in a lower CFR. This difference remained significant even after adjusting resting and CPT velocities for the respective mean BP. Worthy of note, after excluding overweight patients (BMI $>25 \mathrm{~kg} / \mathrm{m}^{2} ; n=5$ ), CPT-derived CFR was again significantly reduced in SHypo normoweight patients $(1.54 \pm 0.2)$ in comparison with normoweight controls $(1.89 \pm 0.2 ; P<0.01)$ and this difference remained significant even after adjusting for mean BP (1.55 \pm 0.3 vs $1.92 \pm 0.2, P<0.01)$. The rate pressure

Table 1 Characteristics of the study population.

\begin{tabular}{|c|c|c|c|}
\hline Clinical data & SHypo $(n=20)$ & Control $(n=15)$ & $\boldsymbol{P}$ \\
\hline Age (years) & $38.4 \pm 12.1$ & $41.4 \pm 14.5$ & 0.59 \\
\hline Body weight (kg) & $67.1 \pm 10.9$ & $61.7 \pm 8$ & 0.16 \\
\hline Height (m) & $1.62 \pm 0.07$ & $1.62 \pm 0.6$ & 0.97 \\
\hline BMI $\left(\mathrm{kg} / \mathrm{m}^{2}\right)$ & $25.5 \pm 2.9$ & $23.5 \pm 2.4$ & $<0.05$ \\
\hline Glycemia (mg/dl) & $86.2 \pm 8.9$ & $84.5 \pm 6.5$ & 0.68 \\
\hline Total cholesterol $(\mathrm{mmol} / \mathrm{l})$ & $4.43 \pm 0.6$ & $4.37 \pm 0.7$ & 0.80 \\
\hline LDL cholesterol (mmol/l) & $2.74 \pm 0.5$ & $2.64 \pm 0.46$ & 0.22 \\
\hline HDL cholesterol (mmol/l) & $1.4 \pm 0.15$ & $1.46 \pm 0.14$ & 0.23 \\
\hline Triglycerides $(\mathrm{mmol} / \mathrm{l})$ & $1.27 \pm 0.36$ & $1.13 \pm 0.26$ & 0.21 \\
\hline Systolic BP (mmHg) & $122.1 \pm 17.5$ & $116.3 \pm 15$ & 0.37 \\
\hline Diastolic BP $(\mathrm{mmHg})$ & $75.7 \pm 8.1$ & $71.7 \pm 10.3$ & 0.38 \\
\hline Mean BP $(\mathrm{mmHg})$ & $91.7 \pm 9$ & $87.2 \pm 10.7$ & 0.33 \\
\hline Heart rate (beats/min) & $76.9 \pm 9.8$ & $78.5 \pm 6.2$ & 0.63 \\
\hline \multicolumn{4}{|c|}{ Hematological and biochemical data } \\
\hline $\mathrm{TSH}(\mathrm{mlU} / \mathrm{l})$ & $7 \pm 2.1$ & $1.9 \pm 0.4$ & $<0.05$ \\
\hline $\mathrm{FT}_{3}(\mathrm{pmol} / \mathrm{l})$ & $4.1 \pm 1.2$ & $4.78 \pm 0.5$ & 0.97 \\
\hline $\mathrm{FT}_{4}(\mathrm{pmol} / \mathrm{l})$ & $15.44 \pm 0.92$ & $16.73 \pm 1.63$ & 0.28 \\
\hline Ab TPO (IÚ/ml) & POS & NEG & \\
\hline
\end{tabular}

Data are expressed as means \pm s.D. BMI, body mass index; BP, blood pressure; POS, positive; NEG, negative. 
Table 2 Doppler echocardiographic analysis.

\begin{tabular}{lccr}
\hline & SH $(n=20)$ & Control $(n=15)$ & $\boldsymbol{P}$ \\
\hline LV mass index $\left(\mathrm{g} / \mathrm{m}^{2}\right)$ & $71.7 \pm 18.7$ & $65.9 \pm 13.2$ & 0.22 \\
Relative wall thickness & $0.3 \pm 0.1$ & $0.3 \pm 0.1$ & 0.38 \\
Endocardial shortening (\%) & $34.5 \pm 5.2$ & $35.1 \pm 5.4$ & $3.4 \pm 0.4$ \\
Left atrial diameter (mm) & $3.4 \pm 0.4$ & $0.6 \pm 0.1$ & 0.77 \\
A peak velocity (m/s) & $0.6 \pm 0.1$ & $0.78 \pm 0.17$ & 0.83 \\
E peak velocity (m/s) & $0.68 \pm 0.21$ & $1.39 \pm 0.44$ & 0.18 \\
Peak velocity E/A ratio & $1.17 \pm 0.35$ & $169.6 \pm 20.2$ & $<.16$ \\
E velocity DT (ms) & $185.5 \pm 25.1$ & $75.7 \pm 13.6$ & $<0.05$ \\
IVRT (ms) & $87.6 \pm 9.9$ & & $<0.05$
\end{tabular}

Data are expressed as means \pm S.D. DT, deceleration time; IVRT, isovolumic relaxation time; LV, left ventricular and E/A, early-to-late transmitral peak flow velocity ratio.

product (systolic $\mathrm{BP} \times$ heart rate) increased significantly in both the groups $(P<0.05$; data not shown in table), without any intergroup differences. Figures 1 and 2 show CPT-derived CFRs in normal control and in a SHypo patient respectively. In the pooled population, CFR was not significantly related to BMI $(P=0.07)$, heart rate $(P=0.83)$, systolic $(P=0.39)$, and diastolic BP $(P=0.08)$, LV mass $(P=0.73)$, endocardial fractional shortening $(P=0.48)$ and indices of $\mathrm{LV}$ diastolic function (A $P=0.65$; E $P=0.13$; $E / A P=0.11$; IVRT $P=0.08)$, fasting blood glucose $(P=0.77)$, total cholesterol $(P=0.28)$, LDL-cholesterol $(P=0.46)$, HDLcholesterol $(P=0.56)$, and triglycerides $(P=0.28)$. There was a mild but significant correlation between TSH and CFR in the whole cohort $(r=-0.42, P<0.01)$.

\section{Discussion}

We report the novel finding that endothelium-dependent CFR is reduced in middle-aged patients with SHypo. Sympathetic stimulus with CPT raises both heart rate and systolic BP (15); i.e. the myocardial oxygen demand, which is currently estimated based on the rate-pressure product. In our study, the increase in myocardial oxygen demand was associated with a proportionate increase in coronary blood flow in the control group of euthyroid subjects because of endothelial-dependent flow mediated vasodilation. On the contrary, the CPT-induced increase of myocardial blood flow was blunted in SHypo patients. We suggest that impaired endothelial function in the coronary microcirculation is the mechanism underlying the inadequate increase in coronary blood flow in response to the increased oxygen demand of the myocardium in SHypo patients.

It has been reported that thyroid hormone deficiency, including the mild form, impairs vascular function by damaging endothelial function at the level of the peripheral vasculature (3-6). This condition is associated with increased vascular smooth muscle tone, arterial stiffening and intima-media thickness (24-27). Our results extend the finding of SHypoinduced endothelial dysfunction to the coronary circulation. In fact, in the absence of epicardial coronary artery disease, as in our study population of young and middle-aged SHypo patients, the reduction of CFR supports the hypothesis of endothelial dysfunction at the level of the coronary microcirculation (23).

CFR has previously been assessed in SHypo by transthoracic Doppler echocardiography. Impairment of CFR in young and middle-aged SHypo patients due to the reduction of hyperemic coronary flow velocities was identified by using the pharmacological stressors adenosine (11) and dipyridamole (12). These stressors induce coronary vasodilatation by a primarily endothelium-independent mechanism. In fact, only the subsequent increment in coronary blood flow triggers further flow-induced vasodilation, which is endothelium-dependent (13). In the present study,

Table 3 Coronary flow reserve test.

\begin{tabular}{|c|c|c|c|}
\hline Variable & SH $(n=20)$ & Control $(n=15)$ & $\boldsymbol{P}$ \\
\hline Coronary flow velocity at rest $(\mathrm{cm} / \mathrm{s})$ & $22.9 \pm 5.1$ & $20.5 \pm 3.8$ & 0.2 \\
\hline Systolic $\mathrm{BP} \times$ heart rate at rest & $9512.9 \pm 1475.9$ & $8500.8 \pm 2161.4$ & 0.32 \\
\hline Diastolic $\mathrm{BP}$ at rest $(\mathrm{mmHg})$ & $75.7 \pm 8.1$ & $71.7 \pm 10.3$ & 0.27 \\
\hline Mean $\mathrm{BP}$ at rest $(\mathrm{mmHg}) I$ & $91.7 \pm 9$ & $87.2 \pm 10.7$ & 0.16 \\
\hline Coronary flow velocity after CPT $(\mathrm{cm} / \mathrm{s})$ & $32.5 \pm 9.9$ & $39.6 \pm 7.6$ & $<0.05$ \\
\hline Systolic $\mathrm{BP} \times$ heart rate after $\mathrm{CPT}$ & $11269.6 \pm 1249.3$ & $10571.7 \pm 1622.3$ & 0.48 \\
\hline Diastolic BP after CPT (mmHg) & $74.4 \pm 8.7$ & $70.4 \pm 10.9$ & 0.30 \\
\hline Mean BP after CPT $(\mathrm{mmHg})$ & $89.7 \pm 8.8$ & $85.8 \pm 11.2$ & 0.32 \\
\hline CFR & $1.4 \pm 0.2$ & $1.9 \pm 0.3$ & $<0.0001$ \\
\hline Adjusted CFR & $1.4 \pm 0.2$ & $2 \pm 0.3$ & $<0.0001$ \\
\hline
\end{tabular}

Data are expressed as means \pm s.D. $C F R$, coronary flow reserve and $B P$, blood pressure. 


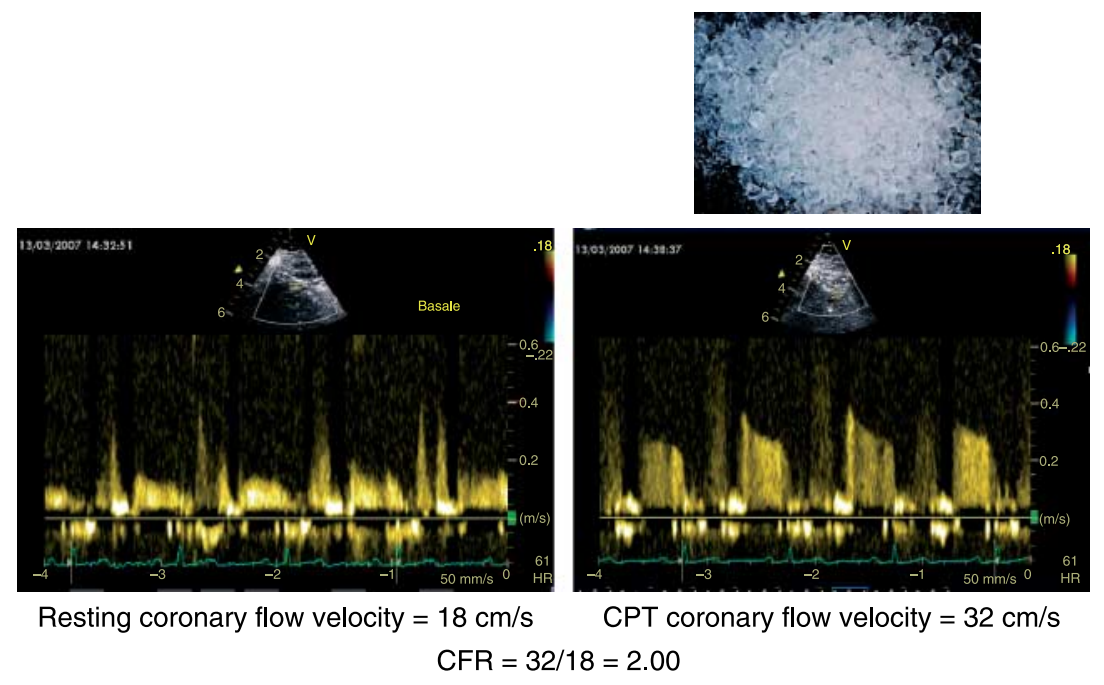

Figure 1 CPT-derived CFRs in healthy euthyroid control subject. we demonstrate that the non-pharmacological stressor CPT is able to reveal a reduced CFR in SHypo patients. Interestingly, the invasively measured coronary flow response to CPT was reported to correlate significantly with flow response to intracoronary acetylcholine administration, an accepted measure of endothelial function (28).

In our study, despite increases in cardiac work (higher pulse-pressure product after CPT than at rest in both patients and controls) the reactive hyperemic flow velocities were significantly reduced in SHypo, which suggests that endothelial dysfunction per se caused the reduced coronary blood flow. The mechanism underlying the coronary endothelial dysfunction in SHypo patients remains to be established. According to an intriguing hypothesis, the deficiency in NO production in the endothelium of the coronary microcirculation causes the altered CFR. NO is believed to be involved in controlling the regulation of coronary tone. It is produced primarily in endothelial cells, and its release is stimulated by several substances and shear stress $(29,30)$. During CPT, increased shear stress stimulates the coronary endothelial cell to release NO, which mediates relaxation of microcirculatory smooth cells and increases perfusion. Animal studies have indicated that thyroid dysfunction can alter capacities for the formation and response to NO (31). A recent study suggests that $\mathrm{T}_{3}$ rapidly stimulates phosphatidylinositol 3-kinase/Akt signaling and increases nitric acid synthase activity 'nitric oxide synthase' in endothelial cells by a receptor-mediated non-genomic action, and thus induces vasodilatation (32). Interestingly, flowmediated dilatation of the brachial artery, a test that evaluates peripheral endothelial function induced by a mechanism of reactive hyperemia similar to that induced by CPT, is reduced in SHypo (33).
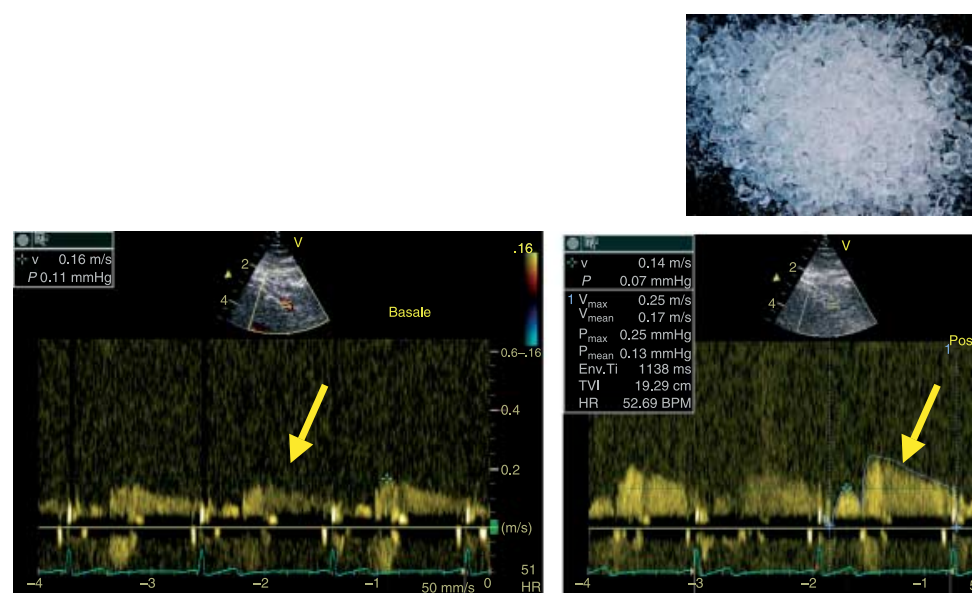

Resting coronary flow velocity $=16 \mathrm{~cm} / \mathrm{s}$

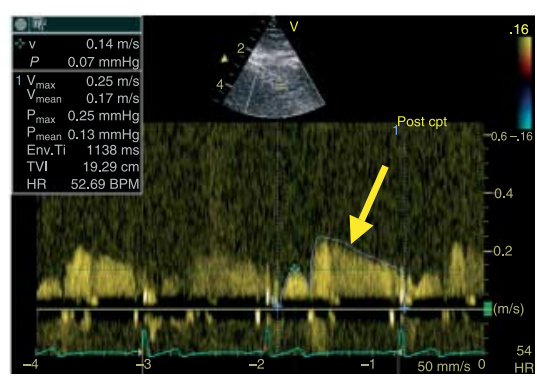

CPT coronary flow velocity $=25 \mathrm{~cm} / \mathrm{s}$

$$
\mathrm{CFR}=25 / 16=1.56
$$

Figure 2 CPT-derived CFRs in a patient with subclinical hypothyroidism. 
Patients affected by SHypo typically have several important atherosclerotic risk factors for coronary artery disease (34-36). Baycan et al. (12) observed an inverse correlation between CFR and BMI in their SHypo patients, and Oflaz et al. (11) found that CFR was closely correlated with HOMA levels in overt and SHypo patients with increased insulin. Moreover, a reduced CFR is associated with arterial hypertension $(21,37)$, diabetes mellitus $(38,39)$, cigarette smoking $(40)$, and insulin-resistance conditions $(41,42)$ in the general population. We therefore selected young and middleaged patients with stable mild thyroid hormone deficiency and excluded subjects with obesity, dyslipidemia, arterial hypertension, diabetes mellitus or hyperinsulinemia, all of which are confounding factors that can affect coronary flow. Only BMI was marginally higher in patients with SHypo than in controls; however, CFR remained significantly lower after CPT even after excluding overweight patients. Moreover, no significant relation was found between CFR and BMI in our group of SHypo patients.

The impairment of endothelial function and reduced CFR are early signs of vascular disease and could herald atherosclerosis and coronary artery disease in our middle-aged SHypo patients. The risk of atherosclerosis and coronary artery disease in patients with a mild form of thyroid hormone deficiency differs among studies because of differences in the age and sex of the populations studied (36). An increased risk of coronary artery disease has been reported in epidemiological studies of young and middle-aged patients (43-45), whereas SHypo does not seem to affect atherosclerosis and coronary artery disease in elderly subjects (36, 46-49).

Another important question is whether the coronary vasomotor abnormality is reversible. Two studies, one double-blind (5) and the other with a double-blind cross-over design (50), have demonstrated that endothelial dysfunction of the peripheral vasculature is reversible in SHypo patients because it regresses after replacement therapy with L-thyroxine. In these patients, L-thyroxine restored NO availability thereby resulting in TSH normalization. In the present study a mild but significant inverse relation was found between TSH levels and CPT-derived CFR. Furthermore, large randomized trials are needed to evaluate the potential benefits of replacement therapy on CFR in SHypo patients without associated cardiovascular risk factors.

\section{Declaration of interest}

The authors hereby declare that there is no conflict of interest that could be perceived as prejudicing the impartiality of the research reported.

\section{Funding}

This research did not receive any specific grant from any funding agency in the public, commercial or not-for-profit sector.

\section{References}

1 Lerman A, Cannan CR, Higano SH, Nishimura RA \& Holmes DR Jr. Coronary vascular remodeling in association with endothelial dysfunction. American Journal of Cardiology 199881 1105-1109.

2 Zeiher AM, Drexler H, Wollschläger H \& Just H. Modulation of coronary vasomotor tone in humans. Progressive endothelial dysfunction with different early stages of coronary atherosclerosis. Circulation 199183 391-401.

3 Lekakis J, Papamicheal C, Alevizaki M, Piperingos G, Marafelia P, Mantzos J, Stamatelopoulos S \& Koutras DA. Flow mediated, endothelium-dependent vasodilation is impaired in subjects with hypothyroidism, borderline hypothyroidism, and high normal serum thyrothropin (TSH) values. Thyroid 1997 7 411-414.

4 Dagre AG, Lekakis JP, Protogerou AD, Douridas GN, Papaioannou TG, Tryfonopoulos DJ, Papamichael CM \& Alevizaki M. Abnormal endothelial function in female patients with hypothyroidism and borderline thyroid function. International Journal of Cardiology $2007114332-338$.

5 Taddei S, Caraccio N, Virdis A, Dardano A, Versari D, Ghiadoni L, Salvetti D, Ferranini E \& Monzani F. Impaired endotheliumdependent vasodilatation in subclinical hypothyroidism: beneficial effect of levothyroxine therapy. Journal of Clinical Endocrinology and Metabolism 200388 3731-3737.

6 Shavdatuashvili T. Lipoprotein profile and endothelial function in patients with subclinical and overt hypothyroidism. Georgian Medical News 2005129 57-60.

7 Bartel T, Yang Y, Muller S, Wenzel RR, Baumgart D, Philipp T \& Erbel R. Noninvasive assessment of microvascular function in arterial hypertension by transthoracic Doppler harmonic echocardiography. Journal of the American College of Cardiology 200239 2012-2018.

8 Britten MB, Zeiher AM \& Schachinger V. Microvascular dysfunction in angiographically normal or mildly diseased coronary arteries predicts adverse cardiovascular long-term outcome. Coronary Artery Disease 200415 259-264.

9 Caiati C, Montaldo C, Zedda N, Bina A \& Iliceto S. A new noninvasive method for coronary flow reserve assessment: contrast enhanced transthoracic second harmonic echo Doppler. Circulation 199999 771-778.

10 Lambertz H, Tries HP, Stein T \& Lethen H. Noninvasive assessment of coronary flow reserve with transthoracic signal-enhanced Doppler echocardiography. Journal of the American Society of Echocardiography 199912 186-195.

11 Oflaz H, Kurt R, Cimen A, Elitok A, Onur I, Golcuk E, Demirturk M, Batmaz S \& Kasikcioglu E. Coronary flow reserve is also impaired in patients with subclinical hypothyroidism. International Journal of Cardiology 2007120 414-416.

12 Baycan S, Erdogan D, Caliskan M, Pamuk BO, Ciftci O, Gullu H, Yildirir A, Guvener ND \& Muderrisoglu H. Coronary flow reserve is impaired in subclinical hypothyroidism. Clinical Cardiology 2007 $30562-566$.

13 Shiode N, Morishima N, Nakayama K, Yamagata T, Matsuura H \& Kajiyama G. Flow-mediated vasodilation of human epicardial coronary arteries: effect of inhibition of nitric oxide synthesis. Journal of the American College of Cardiology 199627 304-310.

14 Zeiher AM, Drexler H, Wollschlaeger H, Saurbier B \& Just H. Coronary vasomotion in response to sympathetic stimulation in humans: importance of the functional integrity of the endothelium. Journal of the American College of Cardiology 198914 1181-1190.

15 Egashira K, Inou T, Hirooka Y, Yamada A, Urabe Y \& Takeshita A. Evidence of impaired endothelium-dependent coronary vasodilatation in patients with angina pectoris and normal coronary angiograms. New England Journal of Medicine $1993 \mathbf{3 2 8}$ 1659-1664.

16 Scachinger V, Britten MB \& Zeiher AM. Prognostic impact of coronary vasodilator dysfunction on adverse long-term outcome of coronary artery disease. Circulation 2000101 1899-1906. 
17 Galderisi M, Paolisso G, Tagliamonte MR, Alfieri A, Petrocelli A, de Divitiis M, Varricchio M \& de Divitiis O. Is insulin action a determinant of left ventricular relaxation in uncomplicated essential hypertension? Journal of Hypertension 199715 745-750.

18 Sahn DJ, DeMaria A, Kisslo J \& Weyman A for the Committee of the American Society of Echocardiography. Recommendation regarding quantitation in M-mode echocardiographic measurements. Circulation 197858 1072-1083.

19 Biondi B, Fazio S, Palmieri EA, Carella C, Panza N, Cittadini A, Bonè F, Lombardi G \& Saccà L. Left ventricular diastolic dysfunction in patients with subclinical hypothyroidism. Journal of Clinical Endocrinology and Metabolism $1999 \mathbf{8 4}$ 2064-2067.

20 Vitale G, Galderisi M, Lupoli GA, Celentano A, Pietropaolo I, Parenti N, De Divitiis O \& Lupoli G. Left ventricular myocardial impairment in subclinical hypothyroidism assessed by a new ultrasound tool: pulsed tissue Doppler. Journal of Clinical Endocrinology and Metabolism $2002874350-4355$.

21 Wirch JL, Wolfe LA, Weissgerber TL \& Davies GA. Cold pressor test protocol to evaluate cardiac autonomic function. Applied Physiology, Nutrition, and Metabolism 200631 235-243.

22 Galderisi M, Cicala S, Caso P, De Simone L, D’Errico A, Petrocelli A \& de Divitiis O. Coronary flow reserve and myocardial diastolic dysfunction in arterial systemic hypertension. American Journal of Cardiology 200290 860-864.

23 Galderisi M. Diastolic dysfunction and diabetic cardiomyopathy: evaluation by Doppler echocardiography. Journal of the American College of Cardiology $2006 \mathbf{4 8} 1548-1551$.

24 Biondi B, Palmieri EA, Lombardi G \& Fazio S. Effects of subclinical thyroid dysfunction on the heart. Annals of Internal Medicine 2002 137 904-914.

25 Biondi B. Cardiovascular effects of mild hypothyroidism. Thyroid $200717625-630$.

26 Biondi B \& Klein I. Hypothyroidism as a risk factor for cardiovascular disease. Endocrine 200424 1-13.

27 Ripoli A, Pingitore A, Favilli B, Bottoni A, Turchi S, Osman NF, De Marchi D, Lombardi M, L'Abbate A \& Iervasi G. Does subclinical hypothyroidism affect cardiac pump performance? Evidence from a magnetic resonance imaging study Journal of the American College of Cardiology $2005 \mathbf{4 5}$ 439-445.

28 Zither AM, Drexler H, Wollschlager H \& Just H. Endothelial function of the coronary microvasculature is associated with coronary blood flow regulation in patients with early atherosclerosis. Circulation 1991 84 1984-1992.

29 Suwaidi JA, Hamasaki S, Higano ST, Nishimura RA, Holmes DR Jr \& Lerman A. Long-term follow-up of patients with mild coronary artery disease and endothelial dysfunction. Circulation $2000 \mathbf{1 0 1}$ 948-954.

30 Palmer RM, Ferrige AG \& Moncada S. Nitric oxide release accounts for the biological activity of endothelium-derived relaxing factor. Nature 1987327 524-526.

31 McAllister RM, Albarracin I, Price EM, Smith TK, Turk JR \& Wyatt KD. Thyroid status and nitric oxide in rat arterial vessels. Journal of Endocrinology $2005 \mathbf{1 8 5} 111-119$.

32 Hiroi Y, Kim HH, Ying H, Furuya F, Huang Z, Simoncini T, Noma K, Ueki K, Nguyen NH, Scanlan TS, Moskowitz MA, Cheng SY \& Liao JK. Rapid nongenomic actions of thyroid hormone. PNAS 2006103 14104-14109.

33 Cikim AS, Oflaz H, Cikim K, Umman S, Meric M, Sencer E \& Molvalilar S. Evaluation of endothelial function in subclinical hypothyroidism. Thyroid 200414605.

34 Cappola AR \& Ladenson PW. Hypothyroidism and atherosclerosis. Journal of Clinical Endocrinology and Metabolism $2003 \mathbf{8 8}$ 2438-2444.

35 Duntas LH \& Wartofsky L. Cardiovascular risk and subclinical hypothyroidism: focus on lipids and new emerging risk factors. What is the evidence? Thyroid 200717 1075-1084.

36 Biondi B \& Cooper DS. The clinical significance of subclinical thyroid dysfunction. Endocrine Reviews 200729 76-131.

37 Galderisi M, de Simone G, Cicala S, Parisi M, D’Errico A, Innelli P, de Divitiis M, Mondillo S \& de Divitiis O. Coronary flow reserve in hypertensive patients with hypercholesterolemia and without coronary heart disease. American Journal of Hypertension $2007 \mathbf{2 0}$ 177-183.

38 Cortigiani L, Rigo F, Gherardi S, Sicari R, Galderisi M, Bovenzi F \& Picano E. Additional prognostic value of coronary flow reserve in diabetic and nondiabetic patients with negative dipyridamole stress echocardiography by wall motion criteria. Journal of the American College of Cardiology 200750 1354-1361.

39 Srinivasan M, Herrero P, McGill JB, Bennik J, Heere B, Lesniak D, Davila-Roman VG \& Gropler RJ. The effects of plasma insulin and glucose on myocardial blood flow in patients with type 1 diabetes mellitus. Journal of the American College of Cardiology $2005 \mathbf{4 6}$ $42-48$.

40 Otsuka R, Watanabe H, Hirata K, Tokai K, Muro T, Yoshiyama M, Takeuchi K \& Yoshikawa J. Acute effects of passive smoking on the coronary circulation in healthy young adults. Journal of the American Medical Association 2001286 436-441.

41 Prior JO, Quiñones MJ, Hernandez-Pampaloni M, Facta AD, Schindler TH, Sayre JW, Hsueh WA \& Schelbert HR. Coronary circulatory dysfunction in insulin resistance, impaired glucose tolerance, and type 2 diabetes mellitus. Circulation 2005111 2291-2298.

42 Quiñones MJ, Hernandez-Pampaloni M, Schelbert H, BulnesEnriquez I, Jimenez X, Hernandez G, De La Rosa R, Chon Y, Yang H, Nicholas SB, Modilevsky T, Yu K, Van Herle K, Castellani LW, Elashoff R \& Hsueh WA. Coronary vasomotor abnormalities in insulin-resistant individuals. Annals of Internal Medicine 2004140 700-708.

43 Hak AE, Pols HA, Visser TJ, Drexhage HA, Hofman A \& Witteman JC. Subclinical hypothyroidism is an independent risk factor for atherosclerosis and myocardial infarction in elderly women: the Rotterdam Study. Annals of Internal Medicine 2000 132 270-278.

44 Walsh JP, Bremner AP, Bulsara MK, O'Leary P, Leedman PJ, Feddema P \& Michelangeli V. Subclinical thyroid dysfunction as a risk factor for cardiovascular disease. Archives of Internal Medicine $20051652467-2472$.

45 Imaizumi M, Akahoshi M, Ichimaru S, Nakashima E, Hida A, Soda M, Usa T, Ashizawa K, Yokoyama N, Maeda R, Nagataki S \& Eguchi K. Risk for ischemic heart disease and all-cause mortality in subclinical hypothyroidism. Journal of Clinical Endocrinology and Metabolism 200489 3365-3370.

46 Cappola AR, Fried LP, Arnold AM, Danese MD, Kuller LH, Burke GL, Tracy RP \& Landenson PW. Thyroid status, cardiovascular risk, and mortality in older adults. Journal of the American Medical Association 2006295 1033-1041.

47 Rodondi N, Newman AB, Vittinghoff E, de Rekeneire N, Satterfield S, Harris TB \& Bauer DC. Subclinical hypothyroidism and the risk of heart failure, other cardiovascular events, and death. Archives of Internal Medicine $20051652460-2466$.

48 Gussekloo J, van Exel E, de Craen AJ, Meinders AE, Frolich M \& Westendorp RG. Thyroid status, disability and cognitive function, and survival in old age. Journal of the American Medical Association $20042922591-2599$.

49 Razvi S, Shakoor A, Vanderpump M, Weaver JU \& Pearce SH. The influence of age on the relationship between subclinical hypothyroidism and ischemic heart disease: a meta-analysis. Journal of Clinical Endocrinology and Metabolism 200893 2998-3007.

50 Razvi S, Ingoe L, Keeka G, Oates C, McMillan C \& Weaver JU. The beneficial effect of L-thyroxine on cardiovascular risk factors, endothelial function, and quality of life in subclinical hypothyroidism: randomized, crossover trial. Journal of Clinical Endocrinology and Metabolism 200792 1715-1723.

Received 27 April 2009

Accepted 5 May 2009 